\title{
Hydrothermal Synthesis and Phase Transition Properties of Uniform Free-standing Vanadium Dioxide Nanowires
}

\author{
Ji Haining, Liu Dongqing, Cheng Haifeng, Zhang Chaoyang, Yang Lixiang, \\ Zheng Wenwei
}

Science and Technology on Advanced Ceramic Fibers and Composites Laboratory, National University of Defense Technology, Changsha 410073, China

\begin{abstract}
Vanadium dioxide $\left(\mathrm{VO}_{2}\right)$ undergoes a Mott metal-insulator transition (MIT) close to room temperature, and has been suggested as a candidate for use in smart window and adaptive infrared camouflage. Here we report the synthesis of uniform free-standing $\mathrm{VO}_{2}$ nanowires using a novel hydrothermal method. The synthetic nanowires have typical diameters of $150 \pm 30 \mathrm{~nm}$ and lengths of tens of micrometer. These $\mathrm{VO}_{2}$ nanowires exhibit high crystallinity and a pure monoclinic phase, which were characterized by X-ray diffraction, X-ray photoelectron spectroscopy, high resolution transmission electron microscopy and selected area electron diffraction. Moreover, reversible phase transition properties of $\mathrm{VO}_{2}$ nanowires are monitored via differential scanning calorimetry, variable temperature X-ray diffraction and temperature-dependent Raman spectroscopy. The results show $\mathrm{VO}_{2}$ nanowires obtained exhibit a reversible phase transition with an endothermic phase transition at $65.2{ }^{\circ} \mathrm{C}$ and a narrow hysteresis width of $6.5^{\circ} \mathrm{C}$. These $\mathrm{VO}_{2}$ nanowires should be promising materials for fundamental investigations of nanoscale metal-insulator transitions.
\end{abstract}

Key words: vanadium dioxide; nanowires; hydrothermal; phase transition

\begin{abstract}
Vanadium dioxide $\left(\mathrm{VO}_{2}\right)$ is one of the most interesting materials owing to its orders-of-magnitude first-order metalinsulator transition (MIT) at a temperature slightly above room temperature $\left(T_{\mathrm{c}}=68{ }^{\circ} \mathrm{C}\right)^{[1]}$. This fortunate circumstance has inspired considerable interest in device architectures that can take advantage of the abrupt switching of electrical and optical properties accompanying this phase transition ${ }^{[2]}$. Exploiting these switching behaviors across the MIT, a number of applications have been demonstrated or proposed in smart window ${ }^{[3-5]}$, optical switches ${ }^{[6-8]}$, Mott transistors ${ }^{[9,10]}$, strain sensors ${ }^{[11-13]}$, and adaptive thermal camouflage ${ }^{[14-17]}$. One-dimensional (1D) $\mathrm{VO}_{2}$ nanowires have attracted a great interest as building blocks used for the fabrication of nanodevices, which triggers a wide range of subsequent research in searching for newer synthetic methods. There have been many existing preparative techniques for this material.
\end{abstract}

Among them, a vapor transport and thermal evaporation are the two major vapor methods to fabricate one-dimensional $\mathrm{VO}_{2}$ nanowires ${ }^{[18-23]}$. In addition to these techniques, it is well conceived that preparation of $\mathrm{VO}_{2}$ nanowires via solution chemical routes provides a promising option for large-scale production of this material. Although they have long been used for $\mathrm{VO}_{2}$ single-crystal nanowires growth $^{[2,24-29]}$, wet-chemical approaches still face the problems of polydispersity and complicated processes in post-synthesis heating treatment. Very recently, single crystalline $\mathrm{VO}_{2}(\mathrm{~A})$ nanowires were synthesized by a hydrothermal method using oxalic acid as reducing agent and polyethylene glycol 6000 as surfactant ${ }^{[30]}$. Although high quality $\mathrm{VO}_{2}(\mathrm{~A})$ nanowires have been obtained, the reported method requires an additional surfactant as additive and cannot produce single-shaped and well-crystallized morphology. Therefore, it is still a

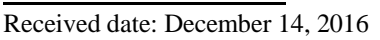

Foundation item: National Natural Science Foundation of China (51502344)

Corresponding author: Cheng Haifeng, Ph. D., Professor, Science and Technology on Advanced Ceramic Fibers and Composites Laboratory, National University of Defense Technology, Changsha 410073, P. R. China, Tel: 0086-731-84576440,E-mail: chf_cfc_nudt@163.com 
meaningful challenge to develop a novel approach for producing uniform free-standing $\mathrm{VO}_{2}$ nanowires in aqueous solution.

In the present work, we report a novel one-step hydrothermal method to synthesize uniform $\mathrm{VO}_{2}$ nanowires with a significant advance in representing the first case for directly synthesizing $\mathrm{VO}_{2}$ nanowires without additional surfactant as additive. Furthermore, the phase-transition properties of $\mathrm{VO}_{2}$ nanowires were studied via variable temperature $\mathrm{X}$-ray diffraction (XRD) and temperature dependent Raman spectroscopy.

\section{Experiment}

All reagents were purchased from Aladdin chemical reagent corporation and used without further purification. $\mathrm{VO}_{2}$ nanowires were prepared by a novel one-step hydrothermal method using a vanadium source of $\mathrm{V}_{2} \mathrm{O}_{5}$ and a reducing agent of stearic acid without additional surfactant as additive. In a typical synthesis, $1.82 \mathrm{~g}$ Vanadium pentoxide $\left(\mathrm{V}_{2} \mathrm{O}_{5}\right.$, analytically pure) and $8.54 \mathrm{~g}$ stearic acid $\left(\mathrm{C}_{18} \mathrm{H}_{36} \mathrm{O}_{2}\right.$, analytically pure) were dispersed in $60 \mathrm{~mL}$ deionized water. The mixture was stirred for $30 \mathrm{~min}$ and then transferred to a $100 \mathrm{~mL}$ Teflon-lined stainless-steel autoclave. The hydrothermal reaction was carried out at $260{ }^{\circ} \mathrm{C}$ for $24 \mathrm{~h}$ and then air-cooled to room temperature. The final products were collected via centrifugation, washed with acetone and ethanol three times and dried in a vacuum drying oven at $80{ }^{\circ} \mathrm{C}$ for $10 \mathrm{~h}$.

Powder XRD characterization of the prepared materials was performed using monochromatic $\mathrm{Cu} \mathrm{K} \alpha$ radiation with a D8ADVANCE diffractometer (Bruker, Germany). Infrared absorption spectra were recorded with a Bruker Vertex 70 FTIR instrument using $\mathrm{KBr}$ pellet method. The morphology was obtained using a field-emission scanning electron microscope (FESEM, NOVA NanoSEM 230). The microstructure of the samples was further analyzed using a transmission electron microscopy (TEM, JEOL2010) with a LaB6 source operating at an acceleration voltage of $200 \mathrm{kV}$. Selected area electron diffraction experiments were carried out in vacuum in a JEOL 2100 transmission electron microscope working at $200 \mathrm{kV}$. X-ray photoelectron spectroscopy (XPS) data were obtained with an ESCALab220i-XL electron spectrometer from VG Scientific using $300 \mathrm{~W} \mathrm{Al} \mathrm{K \alpha}$ radiation. The phase transition behaviors of the resulting products were measured by differential scanning calorimetry (DSC1, METTLER TOLEDO) over the temperature range from 0 to $100{ }^{\circ} \mathrm{C}$ using a liquid nitrogen cooling unit. The heating and cooling rates were set at $10^{\circ} \mathrm{C} / \mathrm{min}$.

Variable temperature XRD data were obtained using a diffractometer (Rigaku TTR-III) equipped with a with a $\mathrm{Cu}$ $\mathrm{K} \alpha$ radiation $(\lambda=0.15418 \mathrm{~nm})$. Under steady $\mathrm{N}_{2}$ flow, the sample was heated (from $30{ }^{\circ} \mathrm{C}$ to $70{ }^{\circ} \mathrm{C}$ ) and cooled (from $70{ }^{\circ} \mathrm{C}$ to $30{ }^{\circ} \mathrm{C}$ ) inside a Rigaku Reactor-X chamber fitted with a Beryllium window. Temperature dependent Raman spectroscopy was recorded using a Horiba JY HR Evolution Spectroscopy System. The excitation wavelength is $532 \mathrm{~nm}$, with laser power kept at $1 \mathrm{~mW}$ to ensure that thermal heating due to the laser focusing does not trigger the MIT. External sample temperature was controlled via a programmable heating- cooling stage.

\section{Materials and Methods}

\subsection{Characterization}

The XRD pattern of a sample obtained at $260{ }^{\circ} \mathrm{C}$ for $24 \mathrm{~h}$ is shown in Fig. 1a as a representative. All peaks can be indexed as a single monoclinic phase $\mathrm{VO}_{2}(\mathrm{M})$ (JCPDS. Card. No. 43-1051). It can also be seen that all of the peaks are sharp and strong with relatively narrow peak widths, indicating the good crystallinity of $\mathrm{VO}_{2}(\mathrm{M})$. The results indicate that phase-pure and well-crystallized $\mathrm{VO}_{2}(\mathrm{M})$ nanowires can be synthesized by such a novel one-step hydrothermal method.

To investigate the chemical bonding between vanadium and oxygen ions and to confirm the phase purity, we performed FTIR spectrum measurement. Fig.1b shows the FTIR spectrum of $\mathrm{VO}_{2}$ (M) sample prepared. The main vibrational bands observed from the FTIR spectrum are at 995, 735, 524, $433 \mathrm{~cm}^{-1}$ and can be considered as intrinsic to vanadium dioxide, which matches well with earlier reports: the initial broad vibrational band at $524 \mathrm{~cm}^{-1}$ and $433 \mathrm{~cm}^{-1}$ are assigned to the $\mathrm{V}-\mathrm{O}-\mathrm{V}$ octahedral bending modes; the band at $995 \mathrm{~cm}^{-1}$ and $735 \mathrm{~cm}^{-1}$ is attributed to the coupled vibration of $\mathrm{V}=\mathrm{O}^{[31-34]}$. These FTIR observations confirm that the nanowires correspond to the $\mathrm{VO}_{2}$ phase.
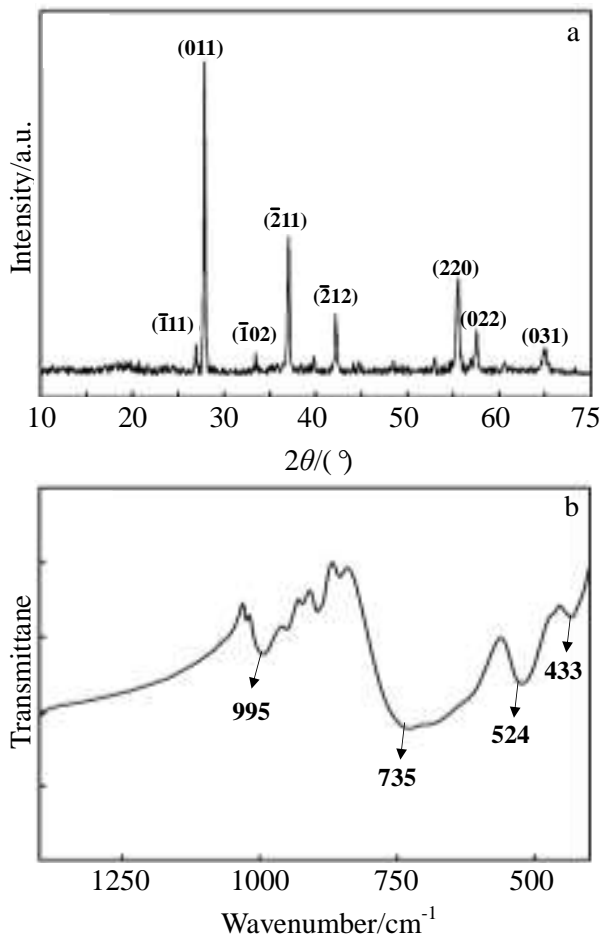

Fig. 1 XRD patterns acquired for as-synthesized $\mathrm{VO}_{2}$ nanowires (a) and FTIR spectrum of $\mathrm{VO}_{2}$ sample prepared (b) 
As shown in Fig. 2, the composition of the $\mathrm{VO}_{2}$ sample is further characterized by XPS. A typical XPS spectrum for the $\mathrm{VO}_{2}$ sample indicates the existence of $\mathrm{V}, \mathrm{O}$ and $\mathrm{C}$ elements, where the carbon is attributed to surface contamination (Fig. 2a). From Fig. 2b, it could be found that the $\mathrm{V} 2 \mathrm{p}_{3 / 2}$ peak of the nanowires is centered at $515.9 \mathrm{eV}$ in good agreement with $516.0 \mathrm{eV}$ of pure $\mathrm{VO}_{2}{ }^{[35]}$. The difference in the binding energy between $\mathrm{O} 1 \mathrm{~s}$ and $\mathrm{V} 2 \mathrm{p}_{3 / 2}$ was $14.1 \mathrm{eV}$, corresponding to that value of literature ${ }^{[36,37]}(14.0 \sim 14.2 \mathrm{eV})$. Fig.2c shows the $\mathrm{Al}$ $\mathrm{K} \alpha$ valence band photoemission spectra for $\mathrm{VO}_{2}$ sample. The spectrum of $\mathrm{VO}_{2}$ has been shifted in energy to place the Fermi level at the top of the known small energy gap, since the $\mathrm{VO}_{2}$ sample shows strong charging effects during the measurements at room temperature ${ }^{[38,39]}$. Combined with $\mathrm{XRD}$, the data of XPS provides an effective evidence of no other vanadium valences in $\mathrm{VO}_{2}(\mathrm{M})$.
The SEM images of the sample in Fig. $3 \mathrm{a}$ and $3 \mathrm{~b}$ reveal strikingly unique wire morphology with typical diameters of $150 \pm 30 \mathrm{~nm}$ and lengths of tens of micrometer. Lattice resolved HRTEM images (Fig.3c) and the selected area electron diffraction (SAED) patterns (Fig.3d) of an individual nanowire corroborate the phase assignment to the monoclinic phase of $\mathrm{VO}_{2}$. The interplanar spacing is calculated to be around 0.332 and $0.484 \mathrm{~nm}$, which is indexed to the $(-111)$ and (100) facets of $\mathrm{VO}_{2}(\mathrm{M})$. SAED patterns in Fig.3d reveal that the $\mathrm{VO}_{2}$ nanowires could be indexed to $\mathrm{VO}_{2}(\mathrm{M})$, which is consistent with XRD patterns.

\subsection{Phase transition}

The fully reversible phase transition of the as-synthesized $\mathrm{VO}_{2}(\mathrm{M})$ nanowires are clearly revealed by DSC curves, variable temperature XRD and temperature-dependent Raman spectroscopy. Fig.4a illustrates that the $\mathrm{VO}_{2}(\mathrm{M})$ nanowires

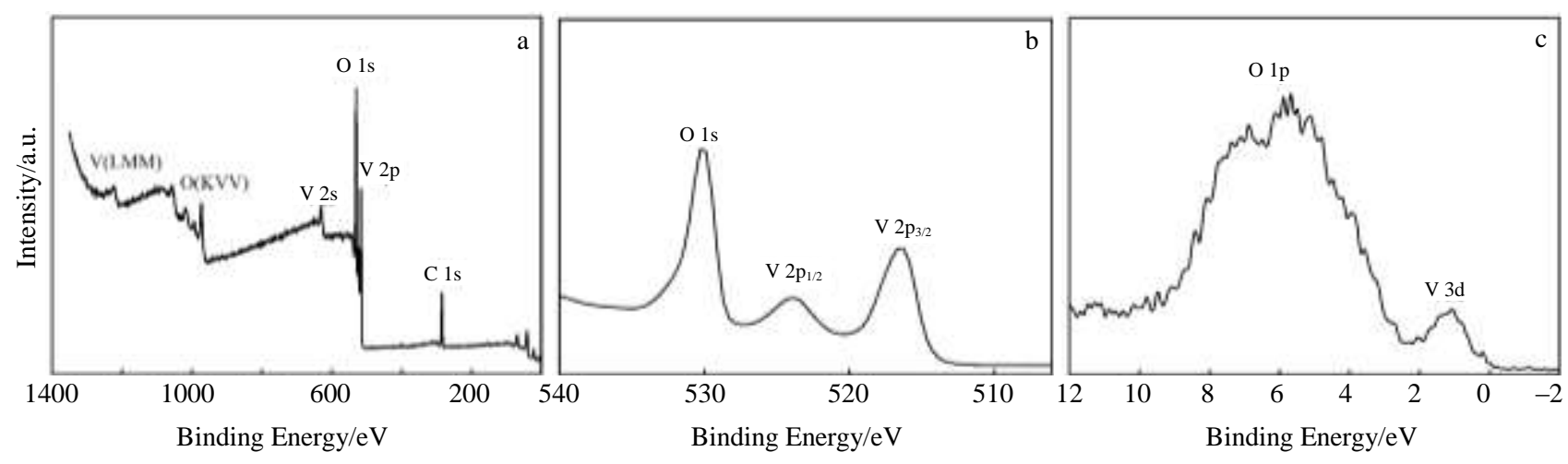

Fig. 2 XPS survey spectra of $\mathrm{VO}_{2}$ sample (a), core-level spectrum of $\mathrm{VO}_{2}$ sample containing V 2p and $\mathrm{O} 1 \mathrm{~s}$ (b), valence band XPS spectra of $\mathrm{VO}_{2}$ sample (c) taken at room temperature

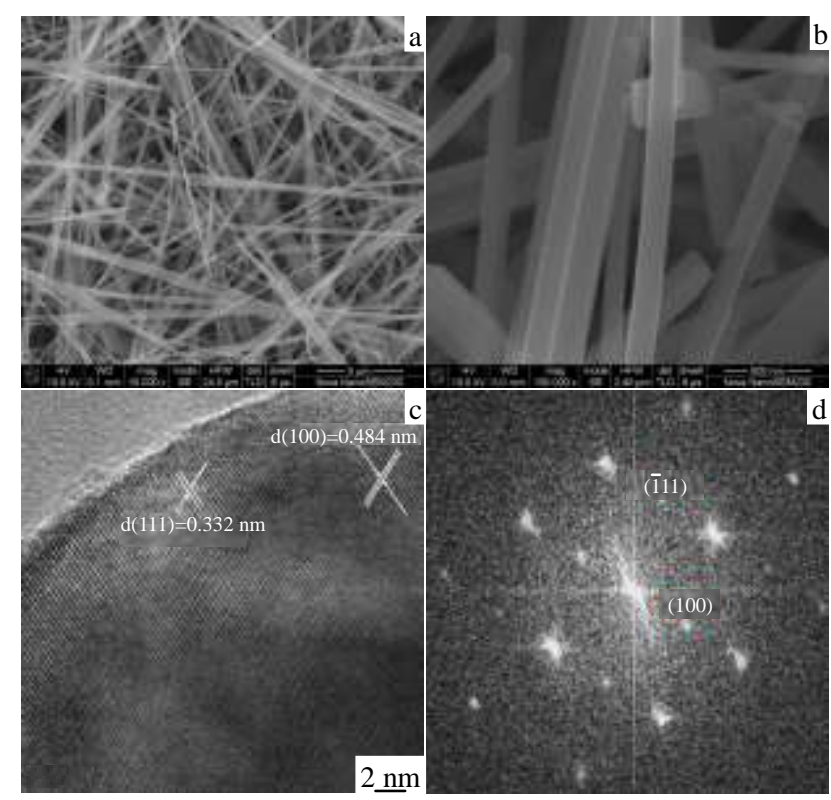

Fig. 3 SEM images (a, b), HRTEM image (c), and SAED patterns (d) of monoclinic $\mathrm{VO}_{2}$ nanowires display a thermal hysteresis phenomenon with a width of $6.5{ }^{\circ} \mathrm{C}$, which is narrower than the results reported in the litera- ture ${ }^{[40,41]}$. This may be caused by the interface effects ${ }^{[42]}$. The heating of the $\mathrm{VO}_{2}(\mathrm{M})$ nanowires is accompanied by endothermal effects at $65.2{ }^{\circ} \mathrm{C}$ in the DSC curves, corresponding to the transition temperature of $\mathrm{VO}_{2}$ from the monoclinic phase $\mathrm{VO}_{2}(\mathrm{M})$ to the tetragonal phase $\mathrm{VO}_{2}(\mathrm{R})$ (see schematic in Fig.4b). Accordingly, the thermal analysis results provide the direct evidence for the occurrence of temperature driven first-order phase transition in $\mathrm{VO}_{2}(\mathrm{M})$ nanowires. Furthermore, the structural phase transition is directly detected using the variable temperature XRD patterns in Fig.5a and 5b. For example, the diffraction peak clearly changes on going from the low-temperature $\mathrm{VO}_{2}(\mathrm{M})$ phase $(011)_{\mathrm{m}}$ peak to the high-temperature $\mathrm{VO}_{2}(\mathrm{R})$ phase $(110)_{\mathrm{r}}$ peak and then to the low-temperature $\mathrm{VO}_{2}(\mathrm{M})$ phase $(011)_{\mathrm{m}}$ peak. Obviously, $\mathrm{VO}_{2}(\mathrm{M})$ can transform to $\mathrm{VO}_{2}(\mathrm{R})$ at $70{ }^{\circ} \mathrm{C}$. This result is nearly consistent with our DSC findings. The metal-insulator transition of $\mathrm{VO}_{2}$ is also verified by the corresponding temperature-dependent Raman spectroscopy in Fig.5c. The low-temperature $\left(30^{\circ} \mathrm{C}\right)$ Raman spectra with 

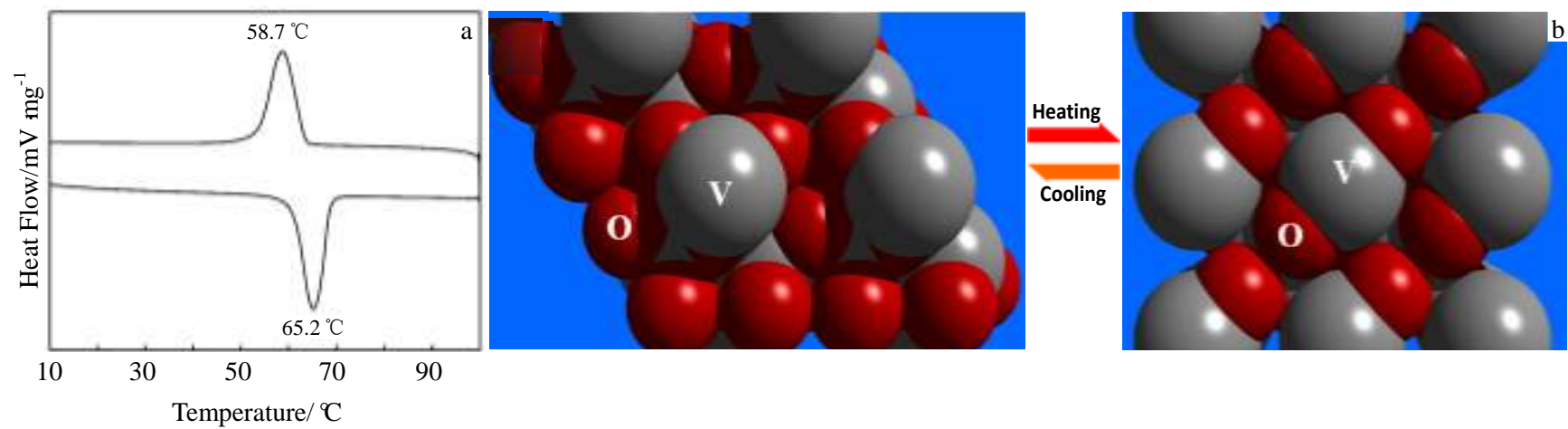

Fig.4 DSC curves of $\mathrm{VO}_{2}(\mathrm{M})$ nanowires (a) and schematic of phase evolution between monoclinic $\mathrm{VO}_{2}(\mathrm{M})$ and tetragonal rutile $\mathrm{VO}_{2}(\mathrm{R})(\mathrm{b})$
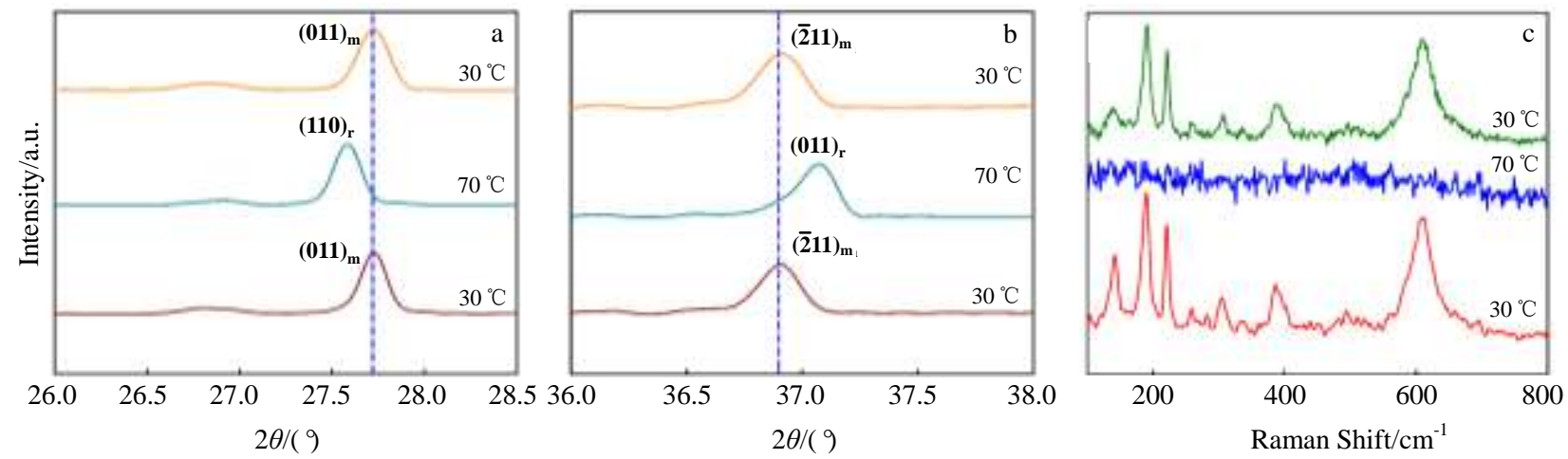

Fig.5 Variable temperature XRD patterns in diffraction angle of $26.0^{\circ} \sim 28.5^{\circ}$ (a), variable temperature XRD patterns in diffraction angle of $36.0^{\circ} \sim 38.0^{\circ}$ (b), and temperature-dependent Raman spectroscopy (c)

peaks at $142,190,222,259,306,339,388,440,497$, and 613 $\mathrm{cm}^{-1}$ could be assigned to the as-obtained $\mathrm{VO}_{2}(\mathrm{M})$ nanowires ${ }^{[20,43-44]}$. When the temperature rises to $70{ }^{\circ} \mathrm{C}$, these Raman peaks vanish due to the transformation into $\mathrm{VO}_{2}(\mathrm{R})$. However, when the temperature is reduced to $30{ }^{\circ} \mathrm{C}$, Raman peaks appears again. Therefore, the evolution of Raman spectra as a function of temperature further evidences the reversible phase transition between $\mathrm{VO}_{2}(\mathrm{M})$ and $\mathrm{VO}_{2}(\mathrm{R})$ nanowires.

\section{Conclusions}

1) Uniform free-standing $\mathrm{VO}_{2}$ nanowires can be synthesized via a novel hydrothermal process using a vanadium source of $\mathrm{V}_{2} \mathrm{O}_{5}$ and a reducing agent of stearic acid without additional surfactant as additive.

2) The synthetic $\mathrm{VO}_{2}$ nanowires exhibit high crystallinity and feature a pure monoclinic phase and composition.

3) $\mathrm{VO}_{2}$ nanowires obtained exhibit a reversible monoclinic to tetragonal structural transition with a metal-insulator transition at $65.2{ }^{\circ} \mathrm{C}$ and a narrow hysteresis width of $6.5^{\circ} \mathrm{C}$.

4) The distinct structural transition between $\mathrm{VO}_{2}(\mathrm{M})$ and $\mathrm{VO}_{2}(\mathrm{R})$ nanowires is further verified by the corresponding variable temperature XRD and temperature-dependent Raman spectroscopy, which would help us understand the mechanism on phase transition for the advanced applications of $\mathrm{VO}_{2}$ based nanodevices.

\section{References}

1 Eyert V. Annalen Der Physik[J], 2002, 11: 650

2 Horrocks G A, Singh S, Likely M F et al. ACS Applied Materials \& Interfaces[J], 2014, 6: 15726

3 Zhou J D, Gao Y F, Zhang Z T et al. Scientific Reports[J], 2013(3): 3029

4 Gao Y F, Luo H J, Zhang Z T et al. Nano Energy[J], 2012(1): 221

5 Warwick M E A, Binions R. Journal of Materials Chemistry A[J], 2014(2): 3275

6 Makarevich A M, Sadykov I I, Sharovarov D I et al. Journal of Materials Chemistry C[J], 2015(3): 9197

7 Zhang Y F, Zhang J C, Zhang X Z et al. Materials Letters [J], 2013, 92: 61

8 Zhang Y B, Huang W X, Song L W et al. Journal of Inorganic Materials[J], 2013, 28: 229

9 Ji H, Wei J, Natelson D. Nano Letters[J], 2012, 12: 2988

10 Hormoz S, Ramanathan S. Solid-State Electronics[J], 2010, 54: 654

11 Wu C Z, Feng F, Xie Y. Chemical Society Reviews[J], 2013, 42: 5157 
12 Li S T, Li Y M, Jiang M et al. ACS Applied Materials \& Interfaces[J], 2013(5): 6453

13 Cao J, Ertekin E, Srinivasan V et al. Nature Nanotechnology[J], 2009(4): 732

14 Xiao L, Ma H, Liu J et al. Nano Letters[J], 2015, 15: 8365

15 Mao Z P, Wang W, Liu Y et al. Thin Solid Films[J], 2014, 558: 208

16 Kats M A, Blanchard R, Zhang S Y et al. Physical Review X[J], 2013(3): 041004

17 Ji H N, Liu D Q, Cheng H F et al. RSC Advances[J], 2017(7): 5189

18 Guiton B S, Gu Q, Prieto A L et al. Journal of the American Chemical Society [J], 2005, 127: 498

19 Cheng C, Liu K, Xiang B et al. Applied Physics Letters[J], 2012, 100: 103111

20 Cheng C, Guo H, Amini A et al. Scientific Reports[J], 2014(4): 5456

21 Strelcov E, Lilach Y, Kolmakov A. Nano Letters[J], 2009(9): 2322

22 Sohn J I, Joo H J, Porter A E et al. Nano Letters[J], 2007(7): 1570

23 Kim I S, Lauhon L J. Crystal Growth \& Design[J], 2012, 12: 1383

24 Gui Z, Fan R, Mo W et al. Chemistry of Materials[J], 2002, 14: 5053

25 Yin $\mathrm{H}$, Luo $\mathrm{M}$, Yu $\mathrm{K}$ et al. ACS Applied Materials \& Interfaces[J], 2011(3): 2057

26 Liu J F, Li Q H, Wang $\mathrm{T} \mathrm{H}$ et al. Angewandte Chemie International Edition[J], 2004, 43: 5048

27 Sung-Hwan B, Sangmin L, Hyun K et al. Advanced Materials[J], 2013, 25: 5098

28 Mai L Q, Hu B, Hu T et al. Journal of Physical Chemistry B[J], 2006, 110: 19083
29 Pan M, Zhong H, Wang S et al. Journal of Crystal Growth[J], 2004, 265: 121

30 Liu X, Xiong W, Zheng Y. International Conference on Mechanics, Materials and Structural Engineering[C]. Jaeju-Do, South Korea: ICMMSE, 2016: 1

31 Popuri S R, Miclau M, Artemenko A et al. Inorganic Chemistry [J], 2013, 52: 4780

32 Sediri F, Gharbi N. Materials Science and Engineering B-Solid State Materials for Advanced Technology[J], 2007, 139: 114

33 Sediri F, Gharbi N, Materials Science \& Engineering B[J], 2007, 139: 114

34 Botto I L, Vassallo M B, Baran E J et al. Materials Chemistry \& Physics[J], 1997, 50: 267

35 Ji H N, Liu D Q, Zhang C Y et al. Science of Advanced Materials[J], 2017(9): 861

36 Kang L T, Gao Y F, Luo H J. ACS Applied Materials \& Interfaces[J], 2009(1): 2211

37 Shen N, Dong B, Cao C et al. RSC Advances[J], 2015, 5: 108015

38 Surnev S, Ramsey M G, Netzer F P. Progress in Surface Science [J], 2003, 73: 117

39 Zimmermann R, Claessen R, Reinert F et al. Journal of Physics Condensed Matter [J], 1998(10): 5697

40 Whittaker L, Jaye C, Fu Z G et al. Journal of the American Chemical Society[J], 2009, 131: 8884

41 Song Z, Zhang L, Xia F et al. Inorganic Chemistry Frontiers[J], 2016(3): 1035

42 Zhong L, Li M, Wang H et al. Cryst Eng Comm[J], 2015, 17: 5614

43 Hu B, Ding Y, Chen W et al. Advanced Materials[J], 2010, 22 5134

44 Chen R, Miao L, Liu C et al. Scientific Reports[J], 2015(5): 14087

\title{
均匀自支撑的二氧化钒纳米线的水热合成及相变特性研究
}

\author{
嵇海宁, 刘东青, 程海峰, 张朝阳, 杨力祥, 郑文伟 \\ (国防科技大学 新型陶瓷纤维及其复合材料重点实验室, 湖南 长沙 410073)
}

\begin{abstract}
摘 要: 二氧化钒 $\left(\mathrm{VO}_{2}\right)$ 在接近室温时发生由半导体态向金属态的 Mott 相变, 在智能窗和红外自适应伪装技术领域具有一定的应用 前景。采用一种新颖的水热法制备了均匀自支撑的 $\mathrm{VO}_{2}$ 纳米线。合成的纳米线的直径为 $150 \pm 30 \mathrm{~nm}$, 长度达到几十微米。通过 $\mathrm{X}$ 射线 衍射、X 射线光电子能谱、高分辨透射电镜和选取电子衍射等手段验证了高纯单斜相 $\mathrm{VO}_{2}$ 纳米线的成功制备。而且, $\mathrm{VO}_{2}$ 纳米线的可逆 相变性能采用差示量热扫描、变温 XRD 和变温 Raman 光谱进行了探究。结果表明: $\mathrm{VO}_{2}$ 纳米线升温相变点为 $65.2{ }^{\circ} \mathrm{C}$, 磁滞回线宽度 窄至 $6.5{ }^{\circ} \mathrm{C}$, 具有良好的可逆相变性。这些为 $\mathrm{VO}_{2}$ 纳米线的金属-半导体相变研究提供基础。
\end{abstract}

关键词: 二氧化钒; 纳米线; 水热法; 相变

作者简介: 嵇海宁, 男, 1984 年生, 博士生, 国防科技大学新型陶瓷纤维及其复合材料重点实验室, 湖南 长沙 410073 , 电话: 0731-84576440, E-mail: sdytjhn@126.com 